\title{
Modeling of combined thermal and mechanical action in roller compacted concrete dam by three-dimensional finite element method.
}

\begin{abstract}
A combined thermal and mechanical action in roller compacted concrete (RCC) dam analysis is carried out using a three-dimensional finite element method. In this work a numerical procedure for the simulation of construction process and service life of RCC dams is presented. It takes into account the more relevant features of the behavior of concrete such as hydration, ageing and creep. A viscoelastic model, including ageing effects and thermal dependent properties is adopted for the concrete. The different isothermal temperature influence on creep and elastic modulus is taken into account by the maturity concept, and the influence of the change of temperature on creep is considered by introducing a transient thermal creep term. Crack index is used to assess the risk of occurrence of crack either at short or long term. This study demonstrates that, the increase of the elastic modulus has been accelerated due to the high temperature of hydration at the initial stage, and consequently stresses are increased.
\end{abstract}

Keyword: FEM; Roller compacted concrete dams; Thermal stress; Creep; Mechanical behavior; Crack criterion factor 